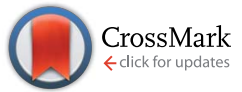

Cite this: RSC Adv., 2017, 7, 14496

Received 23rd December 2016 Accepted 24th February 2017

DOI: 10.1039/c6ra28633j

rsc.li/rsc-advances

\section{Superparamagnetic iron oxide nanoparticles dispersed in Pluronic F127 hydrogel: potential uses in topical applications}

\author{
L. C. Gonçalves, ${ }^{a}$ A. B. Seabra, ${ }^{\text {ab }}$ M. T. Pelegrino, ${ }^{\text {ab }}$ D. R. de Araujo, ${ }^{b}$ J. S. Bernardes ${ }^{c}$ \\ and P. S. Haddad ${ }^{\star a}$
}

The present study is focused on the synthesis and characterization of nitric oxide (NO)-releasing superparamagnetic iron oxide nanoparticles $\left(\mathrm{Fe}_{3} \mathrm{O}_{4} \mathrm{NPS}\right.$ ), and their incorporation in Pluronic F127 hydrogel with great potential for topical applications. Magnetite nanoparticles $\left(\mathrm{Fe}_{3} \mathrm{O}_{4} \mathrm{NPs}\right)$ were synthesized by thermal decomposition of acetylacetonate iron ( $\left.\mathrm{Fe}(\mathrm{acac})_{3}\right)$, and coated with the thiol containing molecule mercaptosuccinic acid (MSA), leading to $\mathrm{Fe}_{3} \mathrm{O}_{4}-\mathrm{MSA}$ NPs. The obtained NPs were characterized using different techniques. The results showed that the $\mathrm{Fe}_{3} \mathrm{O}_{4}-\mathrm{MSA}$ NPs have a mean diameter of $11 \mathrm{~nm}$, in the solid state, and superparamagnetic behavior at room temperature. $\mathrm{Fe}_{3} \mathrm{O}_{4}-\mathrm{MSA}$ NPs have an average hydrodynamic size of $(78.0 \pm 0.9) \mathrm{nm}$, average size distribution (PDI) of $0.302 \pm$ 0.04 , and zeta potential of $(-22.10 \pm 0.55) \mathrm{mV}$. Free thiol groups on the $\mathrm{Fe}_{3} \mathrm{O}_{4}-\mathrm{MSA} \mathrm{NP}$ surface were nitrosated by the addition of sodium nitrite, yielding $S$-nitrosated magnetic nanoparticles $\left(\mathrm{Fe}_{3} \mathrm{O}_{4}-\mathrm{S}\right.$ nitroso-MSA NPs), which act as spontaneous NO donors upon S-N bond cleavage. The amount of (86.4 \pm 4.7) $\mu \mathrm{mol}$ of $\mathrm{NO}$ was released per gram of $\mathrm{Fe}_{3} \mathrm{O}_{4}-\mathrm{S}$-nitroso-MSA NPs. In order to enhance NP dispersion, $\mathrm{Fe}_{3} \mathrm{O}_{4}$-MSA NPs were incorporated in Pluronic $\mathrm{F} 127$ hydrogel $(3.4 \% \mathrm{w} / \mathrm{w})$, and characterized using different techniques. Rheological measurements suggest a potential use for $\mathrm{Fe}_{3} \mathrm{O}_{4}-\mathrm{MSA}$ NPs dispersed in Pluronic hydrogel for topical applications. Atomic force microscopy (AFM) showed that the NPs are embedded within the Pluronic film while the X-ray photoelectron spectroscopy (XPS) spectrum of the $\mathrm{Fe}_{3} \mathrm{O}_{4}-$ MSA NPs samples revealed the presence of iron, oxygen, carbon and sulfur, confirming the presence of MSA molecules on the NP surface.

\section{Introduction}

Superparamagnetic iron oxide nanoparticles, such as $\mathrm{Fe}_{3} \mathrm{O}_{4}$ (magnetite), have been employed in a variety of biomedical applications, including diagnostics and drug delivery. ${ }^{\mathbf{1 - 1 0}}$ Due to the superparamagnetic behavior of $\mathrm{Fe}_{3} \mathrm{O}_{4}$ at room temperature, these NPs have a large constant magnetic moment and act as a giant paramagnetic atom, quickly responding to applied magnetic fields without residual magnetism and coercivity. This behavior makes $\mathrm{Fe}_{3} \mathrm{O}_{4}$ NPs attractive in a number of biomedical applications.

Our group has been synthesizing $\mathrm{Fe}_{3} \mathrm{O}_{4}$ NPs by coprecipitation and thermal decomposition methods, followed by NP surface functionalization with different coatings that can act as carriers of nitric oxide (NO), including thiol molecules such as mercaptosuccinic acid (MSA), dimercaptosuccinic acid

${ }^{a}$ Exact and Earth Science Department, Universidade Federal de São Paulo, UNIFESP, Diadema, SP, Brazil. E-mail: haddadps@gmail.com; Tel: +55 1133854137 (3550)

${ }^{b}$ Human and Natural Sciences Center, Universidade Federal do ABC, UFABC, Santo André, SP, Brazil

${ }^{\circ}$ Brazilian Center for Research in Energy and Materials, CNPEM, Campinas, SP, Brazil
(DMSA), ${ }^{11-14}$ glutathione (GSH), cysteine (Cys), ${ }^{\mathbf{8 , 9 , 1 5}}$ silica, ${ }^{\mathbf{1 6 , 1 7}}$ and polyethylene glycol (PEG). ${ }^{18,19}$ Nitric oxide (NO) is an important biological molecule involved in several physiological processes such as the promotion of wound healing, the control of blood flow, and antimicrobial and anticancer activities. ${ }^{20-24}$ However, as a free radical, the potential therapeutic applications of NO have been limited by its instability and short half-life. ${ }^{25}$ In order to explore the beneficial actions of NO in biomedical applications, low molecular weight NO donors, such as $S$-nitrosomercaptosuccinic acid ( $S$-nitroso-MSA), have been combined with nanomaterials. ${ }^{12}$ In this direction, our group reported the preparation, characterization and cytotoxicity evaluation of versatile nanocarriers by functionalizing the surface of superparamagnetic $\mathrm{Fe}_{3} \mathrm{O}_{4}$ NPs with $S$-nitrosothiol groups, an important class of NO donors. ${ }^{\mathbf{1 1}, \mathbf{1 3}}$ Nevertheless, for biomedical applications, biocompatibility along with aqueous diffuseness and chemical stability of the superparamagnetic nanocarriers are essential issues to be addressed. Although functionalization of $\mathrm{Fe}_{3} \mathrm{O}_{4}$ NPs with low molecular weight thiol-containing molecules, such as MSA, enhanced NP dispersion in aqueous solution, there is a limit for iron oxide NP dispersion in hydrophilic media. In order to overcome this limitation, in this 
study $\mathrm{Fe}_{3} \mathrm{O}_{4}$-MSA NPs were incorporated in the amphiphilic Pluronic F127 hydrogel, to enhance the NP dispersion. Pluronic F127 copolymers are well known to increase biocompatibility and blood circulation time en,27 $^{26}$ and act in pharmaceutical formulation to improve the solubility of hydrophobic drugs. ${ }^{28}$ Pluronic F127 is a triblock polymer composed of polyethylene oxide (PEO) - polypropylene oxide (PPO) - polyethylene oxide (PEO). Several papers have reported the use of Pluronic F127 to stabilize NP suspension by maintaining the high ionic force media, in different pharmaceutical applications. ${ }^{29,30}$ Rodrigues et al. described the synthesis of magnetite NPs by ball milling of $\alpha-\mathrm{Fe}$ in water and its functionalization with oleic acid and Pluronic F127 for hyperthermia applications. ${ }^{31}$ Liu and collaborators investigated synthetic methods of hematite $\left(\alpha-\mathrm{Fe}_{2} \mathrm{O}_{3}\right)$ thin films with Pluronic F127 with different structures and morphologies to provide a material of iron oxides for various biomedical applications. ${ }^{32}$ The authors explored the mechanism formation with variation in the synthetic parameters such as temperature of aging, spin rate in the spin coating, type of substrate, and type of iron reagent to propose new materials. ${ }^{32}$

For biomedical applications, the surface of $\mathrm{Fe}_{3} \mathrm{O}_{4}$ NPs needs to be hydrophilic and biocompatible. However, in the most common synthetic routes to obtain $\mathrm{Fe}_{3} \mathrm{O}_{4}$ NPs, the NPs surface are covered with hydrophobic ligands, making them instable in aqueous suspensions and unsuitable for biomedical applications. Hence, phase transfer methods are required to change the hydrophobic surface coating of the synthesized NP from organic to aqueous dispersion while maintaining its inherent magnetic properties for drug delivery purposes. ${ }^{11,12,33,34}$ Due to its amphiphilic nature, Pluronic F127 is widely used to disperse either hydrophilic molecules, such as $S$-nitrosothiols (RSNOs), or less water soluble particles, such as iron oxides. Moreover, Pluronic F127 was also used to prevent aggregation and protein adsorption along with recognition by reticuloendothelial system (RES). ${ }^{35,36}$ In this context, the aim of this study was to synthesize and characterize $\mathrm{Fe}_{3} \mathrm{O}_{4}$ NPs coated with MSA. The assynthesized $\mathrm{Fe}_{3} \mathrm{O}_{4}$-MSA NPs were: (i) used as NO-releasing superparamagnetic nanocarrier, upon nitrosation of the free thiol groups of MSA, leading to the formation of $\mathrm{Fe}_{3} \mathrm{O}_{4}-S$ nitroso-MSA, (ii) dispersed in Pluronic F127 hydrogel to enhance the NP dispersion in aqueous media and polar solvents and leading to a promising nanomaterial for biomedical applications, in particular, skin-delivery applications, such as nanocarriers for NO delivery in human skin.

Superparamagnetic $\mathrm{Fe}_{3} \mathrm{O}_{4}$ NPs were synthesized by thermal decomposition of $\mathrm{Fe}(\mathrm{acac})_{3}$ and coated with MSA, leading to $\mathrm{Fe}_{3} \mathrm{O}_{4}$-MSA. The morphology, structural and magnetic properties of the NPs were characterized by different techniques. Thiol groups on the surface $\mathrm{Fe}_{3} \mathrm{O}_{4}$-MSA were nitrosated, leading to the formation of $\mathrm{Fe}_{3} \mathrm{O}_{4}-S$-nitroso-MSA, a $\mathrm{NO}$ releasing superparamagnetic nanocarrier. In addition, $\mathrm{Fe}_{3} \mathrm{O}_{4}$-MSA NPs were dispersed in Pluronic $\mathrm{F} 127$ hydrogel $\left(\mathrm{Fe}_{3} \mathrm{O}_{4}\right.$-MSA-F127), which were characterized by X-ray diffraction (XRD), atomic force microscopy (AFM), in vitro permeation using the Franz diffusion cell, and the gelling temperature was evaluated by rheology. Taken together, the results demonstrated the successful incorporation of $\mathrm{Fe}_{3} \mathrm{O}_{4}$-MSA in Pluronic hydrogel showing the potential uses of $\mathrm{Fe}_{3} \mathrm{O}_{4}$-MSA-F127 as drug delivery systems, such as NO donor nanocarriers, in biomedical applications.

\section{Experimental}

\section{Materials and methods}

Materials. Oleic acid (OA), iron(III) acetylacetonate (Fe(acac) $)_{3}$, 1,2-hexadecanediol, benzyl ether, oleylamine, toluene, dimethyl sulfoxide (DMSO), mercaptosuccinic acid (MSA), Pluronic F127 (12 $000 \mathrm{~g} \mathrm{~mol}^{-1}$ ) 5,5'-dithiobis (2-nitrobenzoic acid) (DTNB), phosphate-buffered saline (PBS, pH 7.4), ethylenediaminetetraacetic acid, copper(II) chloride $\left(\mathrm{CuCl}_{2}\right)$, sodium nitrite $\left(\mathrm{NaNO}_{2}\right)$ (Sigma-Aldrich Ch. Co., Inc., USA), hydrochloric acid (12 $\mathrm{mol} \mathrm{L}^{-1}$ ), and ethyl alcohol (LabSynth, Brazil) were used as received. Aqueous solutions were prepared using analytical-grade water from a Millipore MilliQ Gradient filtration system.

Synthesis of $\mathrm{Fe}_{3} \mathrm{O}_{4}$-OA NPs. $\mathrm{Fe}_{3} \mathrm{O}_{4}$ NPs were synthesized through thermal decomposition of $\mathrm{Fe}(\mathrm{acac})_{3}$ in benzyl ether in the presence of $\mathrm{OA}$ and oleylamine by following previously described methods. ${ }^{14}$ Briefly, Fe(acac) ${ }_{3}$ (2 mmol), 1,2-hexadecanediol (10 mmol), benzyl ether $(20 \mathrm{~mL}), \mathrm{OA}(6 \mathrm{mmol})$, and oleylamine $(6 \mathrm{mmol})$ were placed in a reaction flask under continuous $\mathrm{N}_{2}$ flow and vigorous stirring. Under nitrogen atmosphere, the mixture was heated to $265{ }^{\circ} \mathrm{C}$ for $30 \mathrm{~min}$, followed by further heating at $300{ }^{\circ} \mathrm{C}$ for $30 \mathrm{~min}$. The NPs were purified by precipitation using ethanol $(40 \mathrm{~mL})$ and centrifugation (4000 rpm, $20 \mathrm{~min}$ ) to remove the solvent. The obtained NPs were washed three times with ethanol and dried under vacuum.

Adsorption of MSA on $\mathrm{Fe}_{3} \mathrm{O}_{4}$ NPs. The as-synthesized $\mathrm{Fe}_{3} \mathrm{O}_{4^{-}}$ OA NPs $(0.150 \mathrm{~g})$ were dispersed in toluene $(5 \mathrm{~mL})$ while MSA $(0.438 \mathrm{~g})$ was dissolved in DMSO $(5 \mathrm{~mL})$. The dispersions were mixed and magnetically stirred for $14 \mathrm{~h}$ at room temperature, leading to the formation of $\mathrm{Fe}_{3} \mathrm{O}_{4}$-MSA. ${ }^{11}$ Ethanol $(40 \mathrm{~mL})$ was added to the reaction mixture and the black precipitate of $\mathrm{Fe}_{3} \mathrm{O}_{4}$-MSA NPs was separated via centrifugation (4000 rpm, 20 min). The obtained NPs were isolated by magnetic decantation, washed three times with ethanol and dried under vacuum.

\section{Characterization of $\mathrm{Fe}_{3} \mathrm{O}_{4}$-MSA}

Fourier transform infrared (FTIR) spectroscopy. $\mathrm{Fe}_{3} \mathrm{O}_{4}-\mathrm{MSA}$ NPs were triturated with pure potassium bromide $(\mathrm{KBr})$ powder. The mixtures were ground into fine powders, pressed in a mechanical press to generate translucent pellets and analyzed using a Bomen B-100 spectrometer. A pure $\mathrm{KBr}$ pellet was used for the background. The FTIR spectra were recorded from 400 to $4000 \mathrm{~cm}^{-1}$ at a resolution of $4 \mathrm{~cm}^{-1}$.

Hydrodynamic size, size distribution and zeta potential. The hydrodynamic diameter size, polydispersity index (PDI) and zeta potential of $\mathrm{Fe}_{3} \mathrm{O}_{4}$-MSA NPs were measured by dynamic light scattering (DLS) (Nano ZS Zetasizer, Malvern Instruments Corp.) at $25{ }^{\circ} \mathrm{C}$ in polystyrene cuvettes with a path length of 10 $\mathrm{mm}$. The standard report for the size measurement was number using refraction index of 2.0 and absorbance of 0.010 for magnetite. The measurements were performed in triplicate with 
the error bars given as standard deviation from the mean. For all the measurements, the samples were dispersed in deionized water using an ultrasonic bath for $30 \mathrm{~min}$ and filtered through a membrane filter prior the analysis.

Magnetic properties. Magnetization measurements of $\mathrm{Fe}_{3} \mathrm{O}_{4}$ MSA NPs were performed on dried powder, which was slightly pressed and conditioned in a cylindrical Lucite holder. The measurements were performed using a superconducting quantum interference device (SQUID) magnetometer, model MPMS XL 7 from Quantum Design at $300 \mathrm{~K}$.

Nitrosation of free thiol groups on the surface of $\mathrm{Fe}_{3} \mathrm{O}_{4}$-MSA NPs. Free thiol groups on the surface of $\mathrm{Fe}_{3} \mathrm{O}_{4}$-MSA NPs were nitrosated leading to the formation of $S$-nitrosated NPs $\left(\mathrm{Fe}_{3} \mathrm{O}_{4}\right.$ $S$-nitroso-MSA). Aqueous sodium nitrite $\left(60 \mathrm{mmol} \mathrm{L}^{-1}\right)(200 \mu \mathrm{L})$ was added to a $\mathrm{Fe}_{3} \mathrm{O}_{4}$-MSA NP (3.0 mg) suspension previously dispersed in $1 \mathrm{~mL}$ of slightly acidified deionized water $(\mathrm{pH}$ 5.0). ${ }^{37}$ After 30 min of incubation at $10{ }^{\circ} \mathrm{C}$, the obtained $\mathrm{Fe}_{3} \mathrm{O}_{4}-S$ nitroso-MSA NPs suspension was filtered by ultrafiltration using a Microcon centrifugal filter device containing ultrafiltration membranes (10 kDa molar mass cut off (MWCO), Millipore, Billerica, MA, USA) and washed three times with deionized water to remove the excess of unreacted sodium nitrite.

Quantification of NO loaded on the surface of $\mathrm{Fe}_{3} \mathrm{O}_{4}-\mathrm{S}$ nitroso-MSA NPs. The amount of NO loaded on the surface of $S$ nitrosated NPs $\left(\mathrm{Fe}_{3} \mathrm{O}_{4}-S\right.$-nitroso-MSA) was measured by using an NO electrode (2.0 mm ISO-NOP) connected to a TBR4100/ 1025 Free Radical Analyzer (World Precision Instruments, Sarasota, FL, USA). Aliquots of $500 \mu \mathrm{L}$ of aqueous suspensions of $\mathrm{Fe}_{3} \mathrm{O}_{4}$-S-nitroso-MSA NPs $\left(3.2 \mathrm{mg} \mathrm{mL}^{-1}\right)$ were added to the sampling compartment, which contained $10 \mathrm{~mL}$ of aqueous solution copper chloride II $\left(\mathrm{CuCl}_{2}\right)\left(0.1 \mathrm{~mol} \mathrm{~L}{ }^{-1}\right)$. The experiments were performed in triplicate with standard error of the mean. Calibration curve was obtained with additions of aqueous solutions of freshly prepared $S$-nitrosoglutathione (200 $\mu \mathrm{mol} \mathrm{L}{ }^{-1}$ ) (data not shown).

X-ray photoelectron spectroscopy (XPS). The surface composition of $\mathrm{Fe}_{3} \mathrm{O}_{4}$-MSA NPs was analyzed by X-ray photoelectron spectroscopy (XPS), using a K-Alpha X-ray photoelectron spectrometer (Thermo Fisher Scientific, UK) equipped with hemispherical electron analyzer and monochromatic $\mathrm{Al} \mathrm{K} \alpha$ (1486.6 eV) radiation. Peak deconvolution was performed using a $70 \%$ Gaussian and $30 \%$ Lorentzian line shape with a Shirley nonlinear sigmoid-type baseline. The data were analyzed using the Thermo Avantage Software (Version 5.921).

Incorporation of $\mathrm{Fe}_{3} \mathrm{O}_{4}$-MSA NPs in Pluronic F127 hydrogel ( $\mathrm{Fe}_{3} \mathrm{O}_{4}$-MSA-F127). $\mathrm{Fe}_{3} \mathrm{O}_{4}$-MSA NPs $(25 \mathrm{mg}$ ) were dispersed in deionized water $(0.5 \mathrm{~mL})$ using an ultrasonic bath for $30 \mathrm{~min}$. Pluronic $\mathrm{F} 127$ hydrogels containing $\mathrm{Fe}_{3} \mathrm{O}_{4}$-MSA NPs were prepared by the cold method. ${ }^{38}$ Briefly, a solution of Pluronic F127 (35\%) was prepared in PBS buffer ( $\mathrm{pH} 7.4)$. The solution was allowed to attain dissolution equilibrium for a period of $24 \mathrm{~h}$. The previous $\mathrm{Fe}_{3} \mathrm{O}_{4}$-MSA NPs aqueous suspension $(0.5 \mathrm{~mL})$ was added to the Pluronic F127 solution $(2.5 \mathrm{~mL})$, stirred at $5{ }^{\circ} \mathrm{C}$ for homogenization. This procedure led to the dispersion of $\mathrm{Fe}_{3} \mathrm{O}_{4}$-MSA NPs into Pluronic $\mathrm{F} 127$ hydrogel $(3.4 \% \mathrm{w} / \mathrm{w})$, henceforth referred as $\mathrm{Fe}_{3} \mathrm{O}_{4}$-MSA-F127.

\section{Characterization of $\mathrm{Fe}_{3} \mathrm{O}_{4}$-MSA-F127}

X-ray diffractometry (XRD). X-ray diffractograms were obtained with approximately $200 \mathrm{mg}$ powdered $\mathrm{Fe}_{3} \mathrm{O}_{4}$ - $\mathrm{MSA}$ or $\mathrm{Fe}_{3} \mathrm{O}_{4}$ MSA-F127 NPs deposited onto a glass substrate of $2 \mathrm{~cm} \times 2 \mathrm{~cm}$. The measurements were performed in reflection geometry with a conventional X-ray generator (Mo K $\alpha$ radiation of $0.7093 \AA$ and a graphite monochromator) coupled to a scintillation detector; model STADI-P, Stoe ${ }^{\circledR}$. The samples were measured from $12^{\circ}$ to $100^{\circ}(2 \theta)$ with a step size of $0.015^{\circ}(2 \theta)$ and integration time of $120 \mathrm{~s}$ per $3.15^{\circ}$. The crystallite sizes were obtained from the Scherrer equation, based on the (311) Bragg reflection. ${ }^{39}$

In vitro permeation $\mathrm{Fe}_{3} \mathrm{O}_{4}$-MSA-F127 NPs. The in vitro kinetics of iron permeation from the $\mathrm{Fe}_{3} \mathrm{O}_{4}-\mathrm{MSA}-\mathrm{F} 127$ NPs were investigated by using a Franz diffusion cell (standard cell, 15 mm of diameter, $7 \mathrm{~mL}$, Hanson Research Corporation). ${ }^{\mathbf{4 0 4 1}}$ The donor and the receptor chambers were separated by Strat-M ${ }^{\circledR}$ membrane for transdermal diffusion testing which mimics the human skin (Strat-M, Merck Milipore). The donor compartment was filled up with $2.5 \mathrm{~mL}$ of $\mathrm{Fe}_{3} \mathrm{O}_{4}$-MSA-F127 NPs $(3.4 \% \mathrm{w} / \mathrm{w}$ of $\mathrm{Fe}_{3} \mathrm{O}_{4}$-MSA dispersed in Pluronic F127 hydrogel 30\%). The receptor compartment was filled with $10 \mathrm{~mL}$ of $\mathrm{PBS}$ at $\mathrm{pH} 7.4$ and kept under magnetic stirring at $32.5 \pm 0.5{ }^{\circ} \mathrm{C}$. A volume of $0.5 \mathrm{~mL}$ was withdrawn from the receptor compartment, in $30 \mathrm{~min}$ intervals, and replaced by an equivalent volume of fresh PBS for $3 \mathrm{~h}$ of monitoring. ${ }^{\mathbf{4 2 , 4 3}}$ The withdrawn samples were stored at room temperature and the amount of iron leached from the NPs and permeated through the membrane was evaluated through Flame Atomic Absorption Spectroscopy (FAAS).

Determination of permeated iron from $\mathrm{Fe}_{3} \mathrm{O}_{4}-\mathrm{MSA}-\mathrm{F} 127 \mathrm{NPs}$ by FAAS. In order to check if iron was leached from $\mathrm{Fe}_{3} \mathrm{O}_{4}$-MSAF127 NPs applied on the Strat-M® membrane, aliquots withdrawn from the receptor compartment of Franz diffusion cell were added to $\mathrm{HCl}$ aqueous solution $\left(1.0 \mathrm{~mol} \mathrm{~L}^{-1}\right)$. The determinations of iron content in permeated aliquots were performed by FAAS using a spectrometer model SpectrAA 50B (Varian, Australia) and hollow-cathode lamp of iron running according recommendations from manufacturer. The wavelength used for atomic absorption was $248.3 \mathrm{~nm}$. Calibration curves were measured from $\mathrm{FeCl}_{3}$ in $\mathrm{HCl}\left(1.0 \mathrm{~mol} \mathrm{~L}{ }^{-1}\right)$ at different concentrations $\left(0.5,1.0,2.0,4.0\right.$ and $\left.8.0 \mathrm{mg} \mathrm{L}^{-1}\right)$. The measurements were repeated six times for each sample.

Rheology. The rheological measurements of $\mathrm{Fe}_{3} \mathrm{O}_{4}$-MSAF127 NPs (3.4\% w/w) and pure Pluronic F127 hydrogel (35\%) were performed on a rotational rheometer (Kinexus Lab, Malvern Instruments Ltd) with cone-and-plate geometry (diameter $20 \mathrm{~mm}$, angle $0.5 \mathrm{rad}$ and gap between the plates of $1 \mathrm{~mm}$ ) and Peltier temperature control. For determination of elastic $\left(G^{\prime}\right)$ and viscous $\left(G^{\prime \prime}\right)$ moduli, a volume of $1 \mathrm{~mL}$ was transferred to the rheometer and a temperature ramp was applied from 10 to $50{ }^{\circ} \mathrm{C}$ at a heating rate of $5.0^{\circ} \mathrm{C} \mathrm{min}^{-1}$ with a fixed frequency of $1.0 \mathrm{~Hz}$ and a shear stress of $2 \mathrm{~Pa}$. In sequence, the temperature was fixed at $32.5{ }^{\circ} \mathrm{C}$ (in order to simulate the skin application) and a frequency range of $0.1-10 \mathrm{~Hz}$ was applied to evaluate the stability of the material. Each experiment was repeated twice and analyzed using the rSpace software. 
Atomic force microscopy (AFM). The nanoparticles morphology was investigated using an atomic force microscope (NT-MDT, Solver scanning probe microscope) in intermittent contact mode with a nanoworld silicon tip (resonance frequency $=320 \mathrm{kHz}$ ). Prior the microscopy analyses, $10 \mu \mathrm{L}$ of the nanoparticles were deposited on a mica surface and left to dry at room temperature. The AFM data were analyzed using the free Gwyddion 2.45 software and the diameter of the $\mathrm{Fe}_{3} \mathrm{O}_{4}$-MSA NPs were determined from the height to overcome the broadening effect due to AFM tip convolution.

\section{Results and discussion}

\section{Synthesis and characterization of $\mathrm{Fe}_{3} \mathrm{O}_{4}$-MSA NPs}

Among several routes reported to synthesize $\mathrm{Fe}_{3} \mathrm{O}_{4} \mathrm{NPS}^{12,18,44}$ thermal decomposition stands out as an efficient method performed at room temperature and atmospheric pressure, with good control over NP size, composition, morphology and distribution. ${ }^{18,45}$ As-synthesized metallic NPs are generally surfacemodified with hydrophobic ligands, as a strategy to avoid their oxidation and agglomeration, and also to reduce NP polydispersity in organic solvents. ${ }^{11,46}$ However, this strategy generates unstable NPs in aqueous suspension, which limits their biomedical applications. In this study, $\mathrm{Fe}_{3} \mathrm{O}_{4}$ NPs were initially coated with OA, which was then replaced by MSA, a low molecular weight thiol containing molecule. The X-ray photoelectron spectroscopy (XPS) is a powerful tool commonly used to study the chemical composition of materials. Fig. 1a shows the XPS survey spectrum of the $\mathrm{Fe}_{3} \mathrm{O}_{4}$-MSA NPs samples, the peaks were indexed and reveal the presence of iron, oxygen, carbon and sulfur, confirming the successful combination of MSA and $\mathrm{Fe}_{3} \mathrm{O}_{4}$ nanoparticles. In the high-resolution Fe 2p XPS spectrum shown in Fig. 1b, the Fe 2p3/2 and $\mathrm{Fe} 2 \mathrm{p} 1 / 2$ peaks are located at 710.8 and $724.1 \mathrm{eV}$, respectively. The energy difference between these peaks (spin-orbit splitting) is approximately $13.3 \mathrm{eV}$, which is close to the standard value, confirming thus the formation of $\mathrm{Fe}_{3} \mathrm{O}_{4}$ nanoparticles. ${ }^{47,48}$

Fig. 2 shows the FTIR spectra of $\mathrm{Fe}_{3} \mathrm{O}_{4}$ and $\mathrm{Fe}_{3} \mathrm{O}_{4}$-MSA NPs. This technique is useful to identify the most important stretching vibrations of the MSA ligand attached on the nanoparticle surface, as well as characterizing the iron oxide core. ${ }^{49}$ Furthermore, free thiol group (SH) available on the MSA structure can be nitrosated producing NO-releasing nanoparticles, which can then be used as nitric oxide carriers. ${ }^{9,13,50}$ As shown in Fig. 2, the spectrum of uncoated $\mathrm{Fe}_{3} \mathrm{O}_{4}$ NPs displays only a peak at $580 \mathrm{~cm}^{-1}$ assigned to the $(\nu \mathrm{Fe}-\mathrm{O})$. Regarding the FTIR
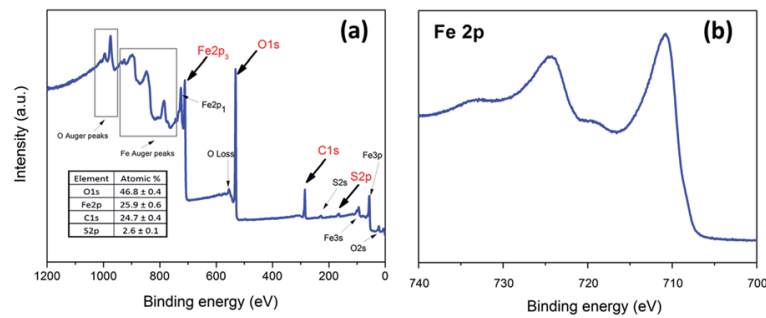

Fig. 1 XPS spectra of $\mathrm{Fe}_{3} \mathrm{O}_{4}$-MSA nanoparticles (a) XPS survey spectrum; (b) high resolution Fe 2p spectrum.

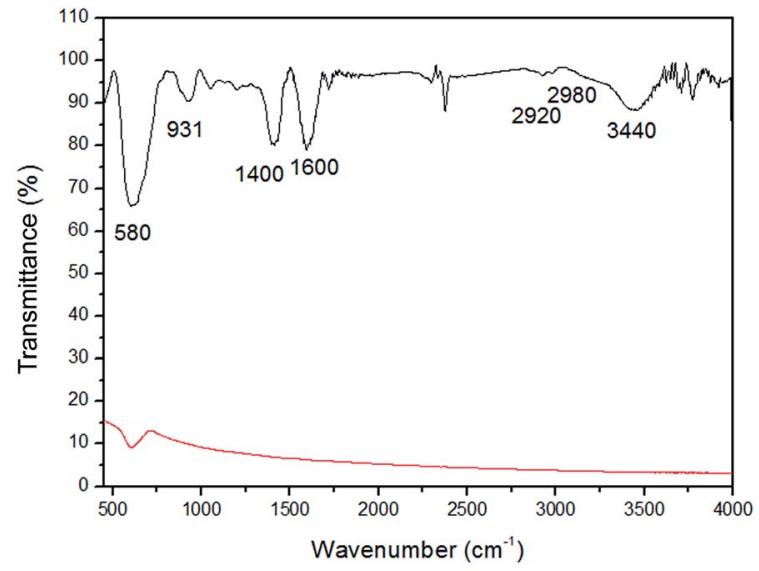

Fig. 2 FTIR spectra of $\mathrm{Fe}_{3} \mathrm{O}_{4}$ NPs (red line) and $\mathrm{Fe}_{3} \mathrm{O}_{4}-$ MSA NPs (black line) in the range $400-4000 \mathrm{~cm}^{-1}$.

spectrum of $\mathrm{Fe}_{3} \mathrm{O}_{4}$-MSA NPs, bands at $580 \mathrm{~cm}^{-1}$ and $3440 \mathrm{~cm}^{-1}$ are assigned to $\mathrm{Fe}-\mathrm{O}(\nu \mathrm{Fe}-\mathrm{O})$ and $\mathrm{FeO}-\mathrm{H}(\nu \mathrm{FeO}-\mathrm{H})$, respectively. ${ }^{9,11}$ The symmetric stretching $\mathrm{COO}^{-}\left(\nu_{\text {sim. }} \mathrm{COO}^{-}\right)$can be observed at $1400 \mathrm{~cm}^{-1}$, while the peak at $1600 \mathrm{~cm}^{-1}$ is attributed to the asymmetric stretching $\left(\nu_{\text {assim. }} \mathrm{COO}^{-}\right)$, to the carboxylate groups. Two small bands at 2920 and $2980 \mathrm{~cm}^{-1} \mathrm{can}$ be attributed to $\mathrm{C}-\mathrm{H}$ stretching $(\nu \mathrm{C}-\mathrm{H})$ of the MSA ligand. The band at $931 \mathrm{~cm}^{-1}$ is attributed to $-\mathrm{CH}$ out of plane bending vibrations of MSA $(\delta \mathrm{C}-\mathrm{H}){ }^{51,52}$ The main band of free $\mathrm{S}-\mathrm{H}$ bond should be observed around $2550 \mathrm{~cm}^{-1}$. $^{53,54}$

The morphology and the average size of $\mathrm{Fe}_{3} \mathrm{O}_{4}$-MSA NPs were evaluated by atomic force microscopy (AFM). Topography and phase contrast images from different regions over the sample surface were obtained and some representative micrographs are shown in Fig. 3. The nanoparticles are spherical in shape with average diameter of $3.9 \pm 1.2 \mathrm{~nm}$. In the sample containing Pluronic (Fig. 3c and d), another important aspect shown by AFM is that the nanoparticles (lighter spots in topography image, Fig. 3c and darker spots in the phase contrast image, Fig. 3d) are embedded within the Pluronic film, as indicated by the yellow arrows.
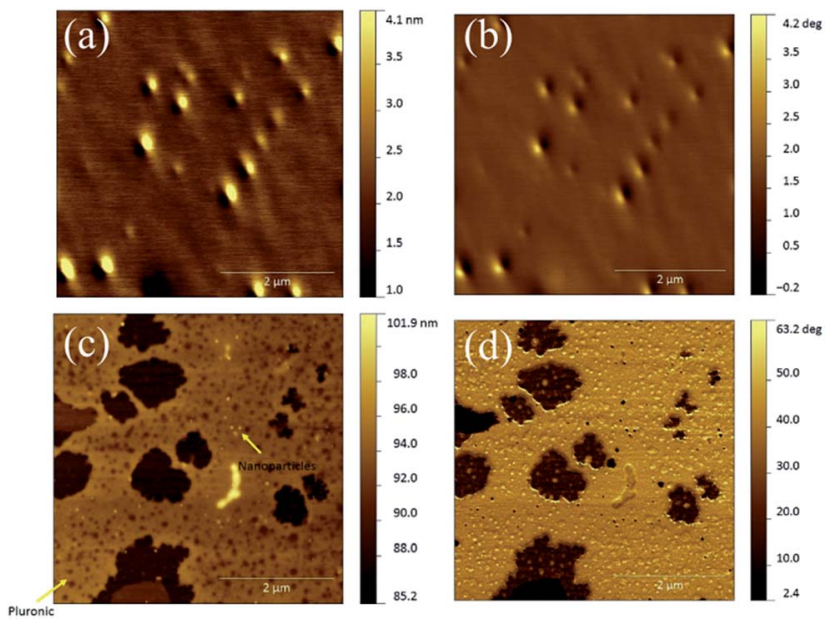

Fig. 3 Topography (left) and phase-contrast image images (right) of $\mathrm{Fe}_{3} \mathrm{O}_{4}-\mathrm{MSA}(\mathrm{a}, \mathrm{b})$ and $\mathrm{Fe}_{3} \mathrm{O}_{4}-\mathrm{MSA}-\mathrm{F} 127$ (c, d). 
The hydrodynamic size of the $\mathrm{Fe}_{3} \mathrm{O}_{4}$-MSA NPs was found to be $78.48 \pm 0.91 \mathrm{~nm}$ and the average size distribution (PDI) was $0.32 \pm 0.04$, indicating moderate polydispersity. Higher hydrodynamic sizes of NPs measured by DLS, in comparison with the sizes obtained by AFM or XRD, are attributed to the presence of extra hydrate layers in aqueous environments. ${ }^{\mathbf{1 0 , 1 8 , 1 9}}$ The zeta potential was $-22.10 \pm 0.55 \mathrm{mV}$. These results indicate that thiolated nanoparticles have a hydrodynamic diameter in the nanoscale and a moderate polydispersity index, indicating a good dispersion in water, which makes these NPs attractive vehicles for drug delivery in biomedical applications.

An important feature of $\mathrm{Fe}_{3} \mathrm{O}_{4}$ NPs for biomedical applications, especially drug delivery, is the superparamagnetic behavior, acting as a single magnetic domain, at temperatures above the blocking temperature..$^{\mathbf{1 0 1 6 , 1 8}}$ The magnetization curve (Fig. 4) of $\mathrm{Fe}_{3} \mathrm{O}_{4}$-MSA NPs reveals that the residual magnetization and coercive force were found to be zero as shown in inset. The saturation magnetization $\left(M_{\mathrm{s}}\right)$ value observed was $59.8 \mathrm{emu}^{-1}$ at room temperature consistent with our previous work..$^{11,16}$ which showed that the addition of the MSA layer on the surface of $\mathrm{Fe}_{3} \mathrm{O}_{4}$ produces a saturation magnetization comparable with that found for $\mathrm{Fe}_{3} \mathrm{O}_{4}$ magnetite. ${ }^{\mathbf{1 1} 17}$ Regarding the addition of an extra non-magnetic layer of MSA on $\mathrm{Fe}_{3} \mathrm{O}_{4}$ NPs surface, a decrease in the $M_{\mathrm{S}}$ value was observed. ${ }^{5,55,56}$ This value is lower than the value observed for $\mathrm{Fe}_{3} \mathrm{O}_{4}$ as-synthesized nanoparticles $\left(\sim 75 \mathrm{emu} \mathrm{g}^{-1}\right)$. It has been reported that $M_{\mathrm{s}}$ tends to decrease when $\mathrm{Fe}_{3} \mathrm{O}_{4}$ NPs are coated with non-magnetic materials. This decrease is attributed to the thiol coating layer, which is responsible for the exchange of electrons between the surface of Fe atoms and the coating material. ${ }^{54}$ This behavior reveals that $\mathrm{Fe}_{3} \mathrm{O}_{4}$-MSA NPs can be transported by an external magnetic field and guided to a specific target, and therefore, can deliver active compounds such as NO directly to the specific site of application.

The addition of MSA on the surface of $\mathrm{Fe}_{3} \mathrm{O}_{4}$ was performed considering electrostatic interactions between the carboxylic group of MSA and the available hydroxyl groups at the surface of the NPs (Fig. 5). In biological applications, the presence of free $\mathrm{SH}$ groups on the surface of NPs provides available site for conjugation with therapeutic molecules, such as NO..10,11

Free thiol groups of $\mathrm{Fe}_{3} \mathrm{O}_{4}$-MSA NPs were nitrosated by the addition of sodium nitrite $\left(\mathrm{NaNO}_{2}\right)$ in slight acidified solution

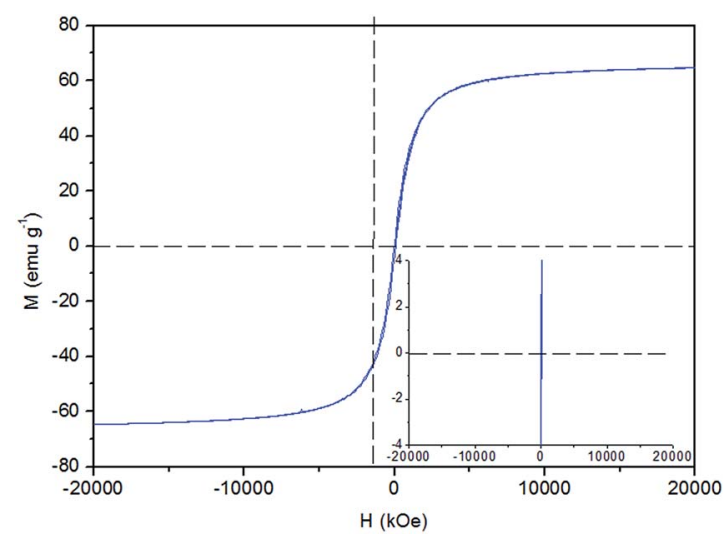

Fig. 4 Magnetic hysteresis curve of $\mathrm{Fe}_{3} \mathrm{O}_{4}$-MSA NPs at $300 \mathrm{~K}$.

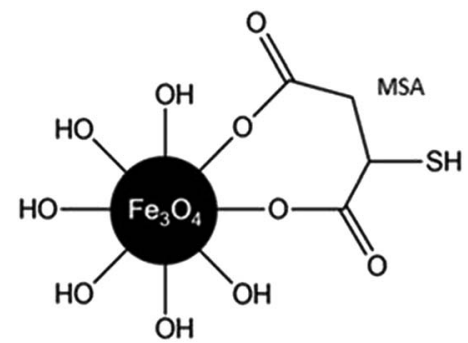

Fig. 5 Schematic representation of the possible interaction between carboxylic group of MSA and the $\mathrm{Fe}_{3} \mathrm{O}_{4}$ NPs surface.

(pH 5.0), leading to the formation of $\mathrm{Fe}_{3} \mathrm{O}_{4}-S$-nitroso-MSA NPs, which act as spontaneous NO donors due to the homolytic S-N cleavage (Fig. 6). The formation of $S$-nitroso-MSA also introduces hydrophilicity, ensuring the stability of $\mathrm{Fe}_{3} \mathrm{O}_{4}$-S-nitrosoMSA NPs in aqueous media, which is important for biomedical applications. ${ }^{10,50}$

In acidified aqueous solution, nitrite $\left(\mathrm{NO}_{2}{ }^{-}\right)$reaches equilibrium with nitrous acid $\left(\mathrm{HNO}_{2}\right) .{ }^{11}$ The formation of this acid is essential to the reaction because it is a potent nitrosating agent of free $\mathrm{SH}$ groups, producing the $\mathrm{SNO}$ groups on the surface of the NPs. $\mathrm{Fe}_{3} \mathrm{O}_{4}-S$-nitroso-MSA NPs undergo spontaneous decomposition, releasing free NO, which is directly dependent on the concentration of $S$-nitroso-MSA groups on the surface of the NPs. Therefore, the quantification of NO loaded on the surface of $\mathrm{Fe}_{3} \mathrm{O}_{4}$-S-nitroso-MSA NPs was performed by monitoring the concentration of NO released from $S$-nitrosated NPs through electrochemical analysis with a specific NO sensor. It was found that the amount of $\mathrm{NO}$ released from $\mathrm{Fe}_{3} \mathrm{O}_{4}-S$-nitroso-MSA NPs was $86.38 \pm 4.71 \mu \mathrm{mol}$ of NO per gram of NPs. As previously reported, ${ }^{57}$ the therapeutic effects of NO in the range of $\mu \mathrm{mol}$ per gram of NPs is related to cell apoptosis induction, which could be explored in cancer treatment, for example. According to the quantitation of $\mathrm{SH}$ groups and $\mathrm{NO}$ released, the $\mathrm{Fe}_{3} \mathrm{O}_{4} \mathrm{NPs}$ are well-suited to carry and deliver therapeutic amounts of $\mathrm{NO}$, due to the capacity of surface functionalization of $\mathrm{Fe}_{3} \mathrm{O}_{4}$ NPs with hydrophilic ligands, such as MSA, following their nitrosation, leading to spontaneous NO release. ${ }^{18,58,59}$

Taken together the results suggest that coating $\mathrm{Fe}_{3} \mathrm{O}_{4}$ NPs with MSA leads to the formation of a stable aqueous dispersion of thiolated superparamagnetic NPs. The free thiol ( $\mathrm{SH}$ ) groups of the MSA ligand were used as sites from which NO was released.

\section{Characterization of $\mathrm{Fe}_{3} \mathrm{O}_{4}$-MSA-F127 NPs}

In order to further increase the utility of $\mathrm{Fe}_{3} \mathrm{O}_{4}$-MSA-F127 NPs, these NPs were incorporated into Pluronic F127 hydrogel matrix to enhance the dispersion of the NPs and allow the topical application of the NPs. Pluronic-involved formation of superparamagnetic $\mathrm{Fe}_{3} \mathrm{O}_{4}$ NPs can yield particles with better aqueousdispersity and lower toxicity. ${ }^{\mathbf{6 0 - 6 2}}$ Indeed, Pluronic have been extensively used for drug delivery due to their thermo-sensitive and amphiphilic properties. The dispersion of $\mathrm{Fe}_{3} \mathrm{O}_{4}$-MSA NPs into the Pluronic matrix combines the magnetic features of these NPs with the biocompatibility and amphiphilicity of F127, enhancing the dispersion of $\mathrm{Fe}_{3} \mathrm{O}_{4}$-MSA NPs in aqueous media 


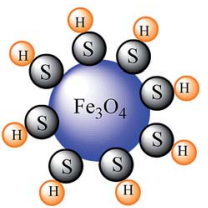

$\mathrm{Fe}_{3} \mathrm{O}_{4}$-MSA
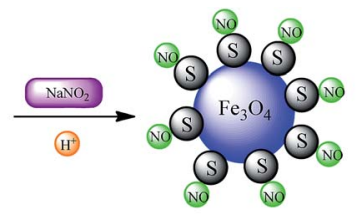

$\mathrm{Fe}_{3} \mathrm{O}_{4}$-S-nitroso-MSA

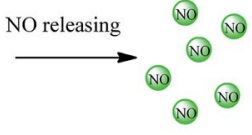

Fig. 6 Schematic representation of the nitrosation of free $\mathrm{SH}$ groups on the surface of $\mathrm{Fe}_{3} \mathrm{O}_{4}$-MSA NPs leading to the formation of $\mathrm{Fe}_{3} \mathrm{O}_{4}$ S-nitroso-MSA.

and polar solvents and leading to a promising nanomaterial for biomedical field. ${ }^{63,64} \mathrm{Fe}_{3} \mathrm{O}_{4}$-S-nitroso-MSA NPs incorporated in Pluronic F127 hydrogel might improve the stability of the SNO groups and consequently provide more precise control of NO release in topical applications. ${ }^{65}$

$\mathrm{X}$-ray diffraction (XRD) analysis was applied to determine the crystal phase of the $\mathrm{Fe}_{3} \mathrm{O}_{4}$-MSA NPs and $\mathrm{Fe}_{3} \mathrm{O}_{4}$-MSA NPs incorporated into $\mathrm{F} 127$ hydrogel. Fig. 7 shows the XRD profiles of $\mathrm{Fe}_{3} \mathrm{O}_{4}$-MSA NPs (black line), $\mathrm{Fe}_{3} \mathrm{O}_{4}$-MSA-F127 NPs (red line) and Pluronic F127 (green line), respectively. The diffractogram of $\mathrm{Fe}_{3} \mathrm{O}_{4}$-MSA NPs (black line) exhibits six reflex peaks that are in agreement with the known reflex positions of magnetite $(2 \theta=$ $13.7^{\circ}, 16.1^{\circ}, 19.4^{\circ}, 23.8^{\circ}, 23.3^{\circ}, 27.6^{\circ}$ ) due to the $220,311,400$, 422,511 , and 440 lattice planes, respectively, of the face centered cubic lattice structure (JCPDS - PDF, 19-0629) ${ }^{66}$ confirming that the structure is $\mathrm{Fe}_{3} \mathrm{O}_{4}$. The inverse spinel structure consists of oxide ions in the cubic close packed organization in which $1 / 3$ of tetrahedral interstices and $2 / 3$ of octahedral interstices coordinate with oxygen where $\mathrm{Fe}^{2+}$ ions occupy the octahedral interstices, and half of the $\mathrm{Fe}^{3+}$ occupies the tetrahedral interstices with the remaining half of $\mathrm{Fe}^{3+}$ in octahedral interstices. ${ }^{12} \mathrm{An}$ average crystallite size of $11 \mathrm{~nm}$ was calculated from the Scherrer equation $^{39}$ based on the (311) Bragg reflection.

In the $\mathrm{Fe}_{3} \mathrm{O}_{4}$-MSA-F127 NPs diffraction data, two strong crystalline peaks observed at $2 \theta=8.8^{\circ}$ and at $10.6^{\circ}$ are attributed to Pluronic F127,67 with additional weak reflections assigned to (311) and (400) magnetite. Therefore, X-ray

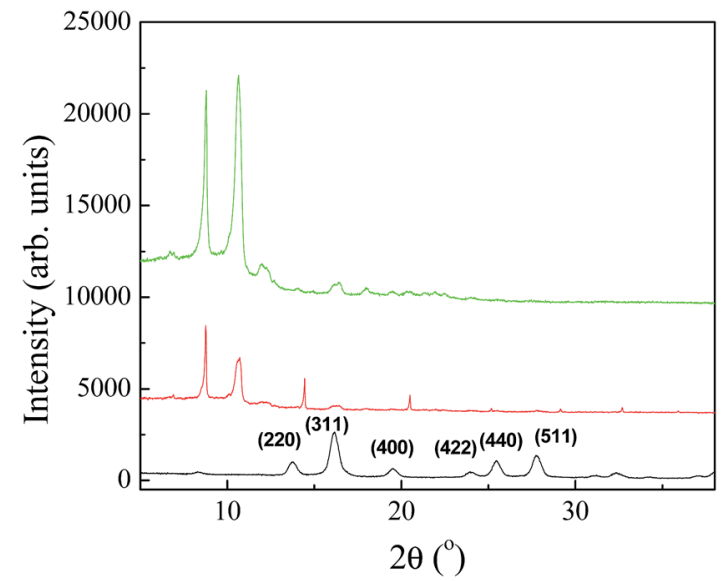

Fig. 7 Diffractograms of $\mathrm{Fe}_{3} \mathrm{O}_{4}-\mathrm{MSA}$ NPs (black line), $\mathrm{Fe}_{3} \mathrm{O}_{4}-\mathrm{MSA}-$ F127 NPs (red line) and Pluronic F127 (green line). diffraction analysis confirmed the incorporation of $\mathrm{Fe}_{3} \mathrm{O}_{4}$-MSA into the Pluronic matrix.

Taking into account the interest for using $\mathrm{Fe}_{3} \mathrm{O}_{4}$-MSA-F127 NPs in biomedical applications, especially for topical uses, it is necessary to consider $\mathrm{Fe}_{3} \mathrm{O}_{4}$ NPs permeation thorough the intact skin, as well as the leaching of iron ions from the NPs through the human skin, which could lead to complications for the human body. Therefore, in order to assess the potential for skin absorption of iron nanoparticles, an in vitro permeation study was performed using a Franz diffusion cell with a Strat-M membrane, which mimics the human skin. Any iron that permeated through the membrane was assayed by atomic absorption spectroscopy. The results demonstrated that no iron permeated from the $\mathrm{Fe}_{3} \mathrm{O}_{4}$-MSA-F127 NPs through the membrane; no signal was detected by atomic absorption spectroscopy, which has a limit of detection (LOD) of $11 \mathrm{mg} \mathrm{L}^{-1}$ and limit of quantification (LOQ) of $37 \mathrm{mg} \mathrm{L}^{-1}$. This result suggests that $\mathrm{Fe}_{3} \mathrm{O}_{4}$ NPs incorporated in Pluronic F127 hydrogel will not absorb in human skin following topical application.

Pluronic F127 is a thermo-responsive biocompatible copolymer and the determination of its sol-gel transition temperature is essential to understand its rheological properties and to determine other parameters, such as viscosity. These properties are important for the use of $\mathrm{Fe}_{3} \mathrm{O}_{4}$-nanoparticles in Pluronic $\mathrm{F} 127$ hydrogel in skin delivery applications. For this reason, rheological measurements of plain $\left(\mathrm{Fe}_{3} \mathrm{O}_{4}\right.$ nanoparticle-free) Pluronic $\mathrm{F} 127$ hydrogel and $\mathrm{Fe}_{3} \mathrm{O}_{4}$-MSA NPs dispersed in Pluronic $\mathrm{F} 127\left(\mathrm{Fe}_{3} \mathrm{O}_{4}\right.$-MSA-F127 NPs) were performed. The parameters measured were the elastic $\left(G^{\prime}\right)$ and viscous $\left(G^{\prime \prime}\right)$ moduli, viscosity $(\eta)$ and the temperature for sol-gel transition ( $T_{\text {sol-gel }}$, observed as an abrupt viscosity increase. Fig. 8 shows representative rheograms for $G^{\prime}$ and $G^{\prime \prime}$ parameters against the temperature range from 0 to $50^{\circ} \mathrm{C}$. All parameters for the hydrogels formulations are presented at Table 1.

All formulations presented viscoelastic behavior, even after the incorporation of $\mathrm{Fe}_{3} \mathrm{O}_{4}$-MSA NPs into Pluronic F127 hydrogel, since $G^{\prime}$ were $\sim 4$ times higher than $G^{\prime \prime}$ values (Table 1 ). The incorporation of iron nanoparticles did not change the temperature behavior inherent to Pluronic hydrogels, but shifted the $T_{\text {sol-gel }}$ transition from 16.3 to $15.7^{\circ} \mathrm{C}$ and the viscosity values, at the skin-temperature, proposed as biological

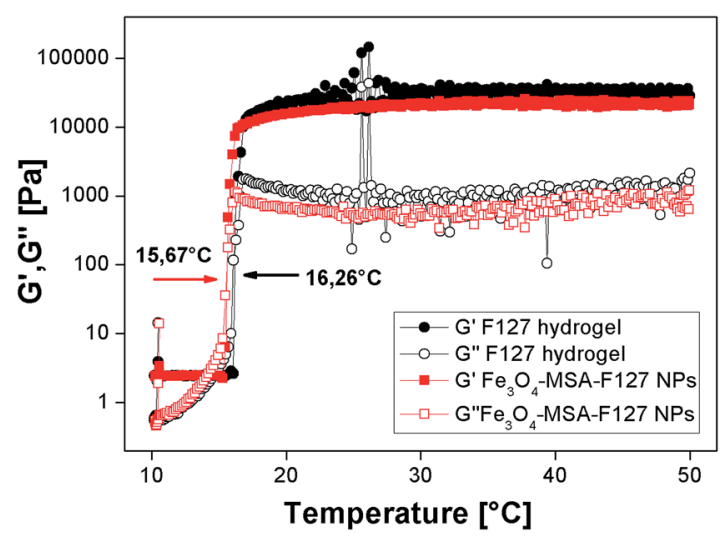

Fig. 8 Elastic $\left(G^{\prime}\right)$ and viscous $\left(G^{\prime \prime}\right)$ moduli for Pluronic F127 hydrogel and $\mathrm{Fe}_{3} \mathrm{O}_{4}-\mathrm{MSA}-\mathrm{F} 127(3.4 \% \mathrm{~W} / \mathrm{w})$ NPs as a function of frequency. 
Table 1 Rheological parameters and $T_{\text {sol-gel }}$ transition for Pluronic F127 hydrogels

\begin{tabular}{|c|c|c|c|c|c|c|}
\hline Formulations & $G^{\prime}(\mathrm{mPa})$ & $G^{\prime \prime}(\mathrm{mPa})$ & $G^{\prime} / G^{\prime \prime}$ & $\eta_{10^{\circ} \mathrm{C}}(\mathrm{mPa} \mathrm{s})$ & $\eta_{32.5^{\circ} \mathrm{C}}(\mathrm{mPa} \mathrm{s})$ & $T_{\text {sol-gel }}\left({ }^{\circ} \mathrm{C}\right)$ \\
\hline F127 hydrogel & 1044 & 246 & 4.2 & 395.2 & 5214000 & 16.26 \\
\hline $\mathrm{Fe}_{3} \mathrm{O}_{4}$-MSA-F127 NPs & 574.9 & 154.5 & 3.7 & 387.3 & 3563000 & 15.67 \\
\hline
\end{tabular}

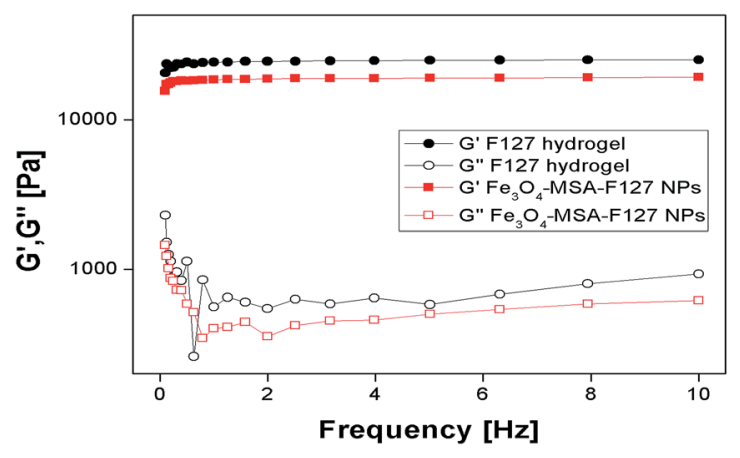

Fig. 9 Rheological parameters for Pluronic F127 hydrogel and $\mathrm{Fe}_{3} \mathrm{O}_{4}$ MSA-F127 NPs as a function of frequency variation at $32.5^{\circ} \mathrm{C}$.

application for that system. In addition, the rheograms obtained at $32.5{ }^{\circ} \mathrm{C}$ after frequency variation showed $G^{\prime}>G^{\prime \prime}$ values, even at lower frequencies, indicating the hydrogels' stability to spreadability and their possible application for skindelivery, as observed in Fig. 9.

\section{Conclusions}

FTIR and NO quantitation measurements of $\mathrm{Fe}_{3} \mathrm{O}_{4}$-MSA NPs confirmed the presence of free thiol groups from MSA as capping agents. $\mathrm{Fe}_{3} \mathrm{O}_{4}$-MSA NPs showed superparamagnetic behavior at room temperature, making these NPs attractive materials for releasing NO. XRD analysis of $\mathrm{Fe}_{3} \mathrm{O}_{4}$-MSA NPs and $\mathrm{Fe}_{3} \mathrm{O}_{4}$-MSAF127 NPs showed the phase purity of $\mathrm{Fe}_{3} \mathrm{O}_{4}$ as magnetite, and that the incorporation of these nanoparticles in the hydrogel matrix did not result in a phase change of iron oxide. AFM corroborated the incorporation of $\mathrm{Fe}_{3} \mathrm{O}_{4}$-MSA NPs in hydrogel matrix with particles of nearly uniform size, low agglomeration and spherical shape. In vitro permeation studies using the Franz diffusion cell method were successful and rheological measurements showed the formulation temperature-dependent and its viscoelastic behavior. The NO-releasing nanomaterial $\left(\mathrm{Fe}_{3} \mathrm{O}_{4}-S\right.$ nitroso-MSA NPs) might find important biomedical applications, due to the importance of NO in skin wound healing. Vehicles that act as NO carriers and donors are extremely attractive for diverse pharmacological applications. This study demonstrated the successful of the incorporation of $\mathrm{Fe}_{3} \mathrm{O}_{4}$-MSA NPs in Pluronic F127 leading to $\mathrm{Fe}_{3} \mathrm{O}_{4}$-MSA-F127 NPs with great potential for biomedical applications.

\section{Acknowledgements}

This study was supported by FAPESP (Procs. 2014/13913-7, 2016/ 10347-6), Newton Advanced Fellowship (The Royal Society
NA140046), Complexo Laboratorial Nanotecnológico (CLN) UFABC - SisNano (Grant number: 402289/2013-7). The authors wish to thank Dr Fanny Nascimento Costa and Prof. Dr Fabio Furan Ferreira (UFABC) for magnetic and X-ray diffraction measurements; Daniel Razzo (UNICAMP) for technical assistance with FE-TEM measurements; Prof. Dr Dario for iron atomic absorption measurements. The authros thank the Brazilian Nanotechnology National Laboratory/Center for Research in Energy and Materials (LNNano/CNPEM) for XPS and AFM analyses.

\section{Notes and references}

1 S. Tarvirdipour, E. Vasheghani-Farahani, M. Soleimani and H. Bardania, Int. J. Pharm., 2016, 501, 331.

2 J. K. Oh and J. M. Park, Prog. Polym. Sci., 2011, 36, 168.

3 C. Sun, J. S. H. Lee and M. Zhang, Adv. Drug Delivery Rev., 2008, 60, 1252.

4 M. Benelmekki, E. Xuriguera, C. Caparros, E. RodríguezCarmona, R. Mendoza, J. L. Corchero, S. Lanceros-Mendez and L. M. Martinez, J. Colloid Interface Sci., 2012, 365, 156.

5 S. H. Hussein-Al-Ali, M. E. Zowalaty El, M. Z. Hussein, B. M. Geilich and T. J. Webster, Int. J. Nanomed., 2014, 9, 3801.

6 W. Lei, W. Min, D. Hui, L. Yun and X. Na, J. Nanosci. Nanotechnol., 2015, 15, 5184.

7 D. Nesztor, K. Bali, I. Y. Tóth, M. Szekeres and E. Tombácz, J. Magn. Magn. Mater., 2015, 380, 144.

8 P. S. Haddad, T. N. Britos, L. M. Li and L. D. S. Li, J. Phys.: Conf. Ser., 2015, 617, 012021.

9 P. S. Haddad, T. N. Britos, M. C. Santos, A. B. Seabra, M. V. Palladino and G. Z. Justo, J. Phys.: Conf. Ser., 2015, 617, 012022.

10 A. B. Seabra, T. Pasquôto, A. C. F. Ferrarini, M. D. C. Santos, P. S. Haddad and R. de Lima, Chem. Res. Toxicol., 2014, 27, 1207.

11 M. M. Molina, A. B. Seabra, M. G. Oliveira, R. Itri and P. S. Haddad, Mater. Sci. Eng., C, 2013, 33, 746.

12 P. S. Haddad and A. B. Seabra, in Iron Oxides: Structure, Properties and Applications, 2012, vol. 1, p. 165.

13 A. B. Seabra, A. J. Paula, R. de Lima, O. L. Alves and N. Durán, Chem. Res. Toxicol., 2014, 27, 159.

14 P. S. Haddad, T. M. Martins, L. D'Souza, L. M. Li, K. Metze, R. L. Adam, M. Knobel and D. Zanchet, Mater. Sci. Eng., C, 2008, 28, 489.

15 A. B. Seabra, M. Rai and N. Duran, J. Plant Biochem. Biotechnol., 2014, 23, 1.

16 K. A. Fudimura, A. B. Seabra, M. D. C. Santos and P. S. Haddad, J. Nanosci. Nanotechnol., 2017, 17, 133.

17 P. S. Haddad, E. L. Duarte, M. S. Baptista, G. F. Goya, C. A. P. Leite and R. Itri, Surf. Colloid Sci., 2004, 128, 232. 
18 M. C. Santos, A. B. Seabra, M. T. Pelegrino and P. S. Haddad, Appl. Surf. Sci., 2016, 367, 26.

19 P. S. Haddad, M. C. Santos, C. A. G. Cassago, J. S. Bernardes, M. B. de Jesus and A. B. Seabra, J. Nanopart. Res., 2016, 18, 369.

20 L. J. Ignarro, Nitric Oxide: Biology and Pathobiology, Academic Press, Waltham, MA, 2000.

21 J. Lei, Y. Vodovotz, E. Tzeng and T. R. Billiar, Nitric Oxide, 2013, 35, 175.

22 A. B. Seabra, E. Pankotai, M. Fehér, A. Somlai, L. Kiss, L. Bíro, C. Szabó, M. Kollai, M. G. de Oliveira and Z. Lacza, Br. J. Dermatol., 2007, 156, 814.

23 A. B. Seabra, R. da Silva, G. F. P. de Souza and M. G. de Oliveira, Artif. Organs, 2008, 32, 262.

24 A. B. Seabra, D. Martins, M. M. S. G. Simões, R. da Silva, M. Brocchi and M. G. de Oliveira, Artif. Organs, 2010, 34, E204.

25 S. K. Choudhari, M. Chaudhary, S. Bagde, A. R. Gadbail and V. Josh, World J. Surg. Oncol., 2013, 11, 118.

26 S. M. Moghimi, Adv. Drug Delivery Rev., 1995, 16, 183.

27 S. Wadhwa, R. Paliwal, S. R. Paliwal and S. P. Vyas, Curr. Pharm. Des., 2009, 15, 2724.

28 A. V. Kabanov, E. V. Batrakova and V. Y. Alakhov, J. Controlled Release, 2002, 82, 189.

29 J. K. Lim, S. A. Majetich and R. D. Tilton, Langmuir, 2009, 25, 13384.

30 M. S. H. Akash and K. Rehman, J. Controlled Release, 2015, 209, 120.

31 E. C. Rodrigues, M. A. Morales, S. N. de Medeiros, N. M. Suguihiro and E. M. Baggio-Saitovitch, J. Magn. Magn. Mater., 2016, 416, 434.

32 J. Liu, Y. T. Kim and Y. U. Know, Nanoscale Res. Lett., 2015, 10, 228.

33 A. Prakash, H. G. Zhu, C. J. Jones, D. N. Benoit, N. Denise, A. Z. Ellsworth, E. L. Bryant and V. L. Colvin, ACS Nano, 2009, 3, 2139.

34 W. L. Li, C. H. Hinton, S. S. Lee, J. W. Wu and J. D. Fortner, Environ. Sci.: Nano, 2016, 3, 85.

35 J. J. Lin, J. S. Chen, S. J. Huang, J. H. Ko, Y. M. Wang, T. L. Chen and L. F. Wang, Biomaterials, 2009, 30, 5114.

36 S. Biswas, K. D. Belfield, R. K. Das, S. Ghosh and A. F. Hebard, Polymers, 2012, 4, 1211.

37 R. de Lima, J. L. de Oliveira, A. Ludescher, M. M. Molina, R. Itri, A. B. Seabra and P. S. Haddad, J. Phys.: Conf. Ser., 2013, 429, 012021.

38 A. B. Seabra, G. de Souza, L. da Rocha, M. Eberlin and M. de Oliveira, Nitric Oxide, 2004, 11, 263.

39 H. P. Klug and L. E. Alexander, X-Ray Diffraction Procedures for Polycrystalline and Amorphous Materials, WileyInterscience, New York, 1974.

40 T. J. Franz, J. Invest. Dermatol., 1975, 64, 190.

41 T. Uchida, W. R. Kadhum, S. Kanai, H. Todo, T. Oshizaka and K. Sugibayashi, Eur. J. Pharm. Sci., 2015, 67, 113.

42 R. Vercelino, T. M. Cunha, E. S. Ferreira, F. Q. Cunha, S. H. Ferreira and M. G. de Oliveira, J. Mater. Sci.: Mater. Med., 2013, 24, 2157; A. C. S. Akkari, E. V. R. Campos,
A. F. Keppler, L. F. Fraceto, E. de Paula, G. R. Tófoli and D. R. de Araujo, Colloids Surf., B, 2016, 138, 138.

43 X. Wang, J. Zhuang, Q. Peng and Y. Li, Nature, 2005, 437, 121. 44 S. Sun, H. Zeng, D. B. Robinson, S. Raoux, P. M. Rice, S. X. Wang and G. Li, J. Am. Chem. Soc., 2004, 126, 273.

45 R. Hufschmid, H. Arami, R. M. Ferguson, M. Gonzales, E. Teeman, L. Brush, N. D. Browningb and K. M. Krishnan, Nanoscale, 2015, 7, 11142.

46 S. K. Yen, D. P. Varma, W. M. Guo, V. H. B. Ho, V. Vijayaragavan, P. Padmanabhan, K. Bhakoo and S. T. Sekvan, Chem.-Eur. J., 2015, 21, 3914.

47 M. C. Biesinger, B. P. Payne, A. P. Grosvenor, L. W. M. Lau, A. R. Gerson and R. S. C. Smart, Appl. Surf. Sci., 2011, 257, 2717.

48 A. P. Grosvenor, B. A. Kobe, M. C. Biesinger and N. S. McIntyre, Surf. Interface Anal., 2004, 36, 1564.

49 R. D. Rutledge, C. L. Warner, J. W. Pittman, R. S. Addleman, M. Engelhard, W. Chouyok and M. G. Warner, Langmuir, 2010, 26, 12285.

50 A. B. Seabra and N. Duran, J. Mater. Chem., 2010, 20, 1624. 51 J. Zhang, S. Rana, R. S. Srivastava and R. D. K. Misra, Acta Biomater., 2008, 4, 40.

52 K. Shameli, M. Bin Ahmad, S. D. Jazayeri, S. Segaghat, P. Shabanzadeh, H. Jahangirian, M. Mahdavi and Y. Abdollahi, Int. J. Mol. Sci., 2012, 13, 6639.

53 F. delMonte, M. P. Morales, D. Levy, A. Fernandez, M. Ocana, A. Roig, E. Molins, K. OGrady and C. J. Serna, Langmuir, 1997, 13, 3627.

54 S. Chawla and K. Jayanthi, Appl. Surf. Sci., 2011, 12, 3925.

55 D. Dorniani, A. U. Kura, M. Z. Bin Hussein, S. Fakurazi,

A. H. Shaari and Z. Ahmad, J. Mater. Sci., 2014, 49, 8487.

56 R. Kumar, B. S. Inbaraj and B. H. Chen, Mater. Res. Bull., 2010, 45, 1603.

57 P. N. Coneski and M. H. Schoenfisch, Chem. Soc. Rev., 2012, 41, 3753.

58 A. Das, P. Mukherjee, S. K. Singla, P. Guturu, M. C. Frost, D. Mukhopadhyay, V. H. Shah and C. R. Patra, Nanotechnology, 2010, 21, 305102.

59 R. Y. Pelgrift and A. J. Friedman, Adv. Drug Delivery Rev., 2013, 65, 1803.

60 N. A. Alsmadi, A. S. Wadajkar, W. Cui and K. T. Nguyen, J. Nanopart. Res., 2011, 13, 7177.

61 S. Fuentes, J. Dubo, N. Barraza, R. Gonzalez and E. Veloso, J. Magn. Magn. Mater., 2015, 377, 65.

62 J. Lai, K. V. P. M. Shafi, K. Loos, Y. Lee, T. Vogt, W. L. Lee and N. Ong, J. Phys. Chem. B, 2005, 109, 15.

63 M. Chiper, K. H. Aubert, A. Augé, J. Fouquenet, M. Soucé and I. Chourpa, Nanotechnology, 2013, 24, 395605.

64 S. R. Sershen, S. L. Westcoot, N. J. Halas and J. L. West, Appl. Phys. Lett., 2002, 80, 4609.

65 S. M. Shishido, A. B. Seabra, W. Loh and M. G. de Oliveira, Biomaterials, 2013, 24, 3543.

66 B. Y. Yu and S. Y. Kawak, J. Mater. Chem., 2010, 20, 8320.

67 Q. Zhou, Z. Zhang, T. Chen, X. Guo and S. Zhou, Colloids Surf., B, 2011, 86, 45. 